\title{
'COUNTING BLACK AND WHITE BEANS': WHY WE NEED A CRITICAL RACE THEORY OF ACCOUNTING
}

\author{
Anton M. Lewis, PhD \\ Saint Xavier University - Graham School of Management \\ Chicago, IL, USA
}

Doi: 10.19044/elp.v2no2a1 URL:http://dx.doi.org/10.19044/elp.v2no2a1

\begin{abstract}
This article calls for accountancy in academia and industry to examine the role of racialized processes in the field using the perspective of Critical Race Theory (CRT). In the United States few Black CPAs exist in proportion to their white peers and only a handful ever reach the level of partner in large accounting firms. A problem that has been left largely unproblematized. Instead assumptions of racial neutrality and an unshakable faith in accountancy as a value free technocracy, untouched by social reality abound. A core belief in accountants exists that sees issues of equality as the work of human resource professionals and sociologists rather than addressing it as a central structural force in the field. This leaves the area of race in accountancy under-theorized and under-researched. A CRT critical framework (re) problematizes poor Black entry and progression, seeking the formation of new strategies to challenge the stratified reality of a gendered and raced profession.
\end{abstract}

Keywords: Racism, Accountancy, Colorblindness, Neutrality, Technocracy

\section{Introduction}

This paper argues that a theory of race in accountancy is needed to explain the low numbers of Black accountants in the profession. Race and racism represent key factors that are difficult to explore because the very idea that racism exists in the accounting profession is treated as taboo. Accountancy treats race as a nonsensical idea, a problem for other professions such as sociology and psychology. Too often assumed to be the sole purview of human resource management not accountancy. The profession deals with numbers and is therefore portrayed as essentially unbiased. A dull boring space where the typical accountant is viewed as a bespectacled bureaucrat. However a number of other disciplines including 
the law have examined racial disparities in their own fields: the question is why? Why do so few Black professionals exist in comparison to white ones? Could it be possible that race and racism does in fact structure many professional fields - including accounting? If so, then an explicit race-based framework would be ideal to explore how institutional and individual racism impacts the profession. Where institutional racism indicates pervasive unseen racial animosity found within organizations and individual racism signifies that aspect of personal prejudice that defines the racialized Other as unbearable.

Critical Race Theory (CRT) is one such framework originally conceived in the field of Law and now used in multiple disciplines to examine how race and oppression impact professions, particularly racial ethnic minorities. Essentially a CRT standpoint centralizes race and racism in society. This view has been applied to diverse areas such as education (Gillborn, 2005; Ladson-Billings \& Tate, 2006), Sport (Hylton, 2009), and Social Studies (Ladson-Billings, 2003) enriching policy and debate in the process. This is not to say that race has been wholly ignored. Certainly Theresa Hammond's seminal work 'A White Collar Profession' provides an excellent historical analysis of exclusion in the African American accounting experience. Hammond et al. continue to examine race in the context of Chartered accountancy in South Africa, while Sian similarly examines processes of racialization in the Kenyan accounting profession. Both Uche's analysis of Nigerian accountancy and Annisette's exploration of the process of imperialism in the formation of the profession in Trinidad and Tobago also add a rich narrative when exploring proto-inclusion and exclusionary race based practice in post-colonial environments. Bakre unpacks similar themes in the context of the failed attempt to create a specifically Jamaican (and therefore predominantly Black) accounting industry. Yet how specific racialized processes interact to create long-term structural exclusion and subordination has not been fully problematized, because specific theories of race and racism are seldom applied to such analysis (Annisette, 2000; Bakre, 2006; Hammond, 2002; Hammond et al., 2007; Hammond, 2002; Sian, 2007; Uche, 2002).

This article engages in such a race specific inquiry by outlining areas of discussion and research agendas that place race at the heart of analysis, to begin to again examine the question of low Black representation in the profession from a differing theoretical perspective. The first section looks at the current paucity of Black accountants, while section two defines CRT and its value in unpacking issues of race and racism in the field. Section three explores the nature of racism that is a daily occurrence in the workplace and section four examines what identity might mean for the Black accountant in a racialized professional environment. 


\section{Race and Accountancy}

For many in the profession the very of notion of racism seems antithetical, the following question is often thought but seldom said 'but how can racism be prevalent in our field?' To begin to answer this we must look at the data. Unfortunately, little exists either quantitative or qualitative which comprehensively examines racism or the reason behind the low number of Black accountants as a whole (Lewis, 2012). But despite the general dearth of data available historic 1995 racial statistics from the American Institute of CPA's (AICPA) suggested that $2 \%$ of professional staff at Certified Public Accounting (CPA) firms were Black. Only $1 \%$ of Blacks were partners or owners of CPA firms. The picture painted is a worrying portrait of Black accountancy (Malone, 2001; Ross \& Traub, 2010). Two years later only $0.75 \%$ to $0.99 \%$ of African Americans in 1997 as a whole were counted as licensed Certified Public Accountants (CPAs) (Hammond, 2002).

However, the 2013 Bureau of Labor Statistics has reported that even though $77.8 \%$ of accountants and auditors employed were white, $8.6 \%$ were Black or African American (Bureau of Labor Statistics, 2014). While these numbers indicate a marked improvement a distinct gap between Black and white participation in the profession still exists that is wide and still largely unexplained. Perhaps of more concern is the static nature of a problem that has not changed in well over 20 years. This is reflected in the fact that the National Association of Black accountants (NABA) only have $23 \%$ of their own membership qualified as licensed CPAs. Again, pointing to the difficulty of certification for African American accountants (Ross \& Traub, 2008).

Figures from the Center For Accounting Education (CAE) at Howard University further suggest that only $1 \%$ of public accounting partners are Black and only $3 \%$ of fortune 500 CEO's are from ethnic minorities (meaning less than $1 \%$ will be Black). More worrying still, the AICPA highlights in its 2011 Trends in the Supply of Accounting Graduates and the Demand for Public Accounting Recruits report that minorities consist of only $20 \%$ of professional staff positions of 348 firms that took part. A mere 5\% reported that minorities were partners at those firms (Tysiac, 2012). A CAE symposium attended by Big 4 and mid-tier stakeholders, elaborated on the nature of retention and upward mobility of African American accountants where the subject of taboo areas was addressed:

"...Topics such as subtle racism can be uncomfortable and we are less likely to raise them - especially when the room includes people of different racial backgrounds. Putting these topics off limits means we sidestep some significant challenges" (Ross \& Traub, 2010, p. 15). 
Why are such discussions uncomfortable? Recently accountancy organizations have been at the forefront of raising the importance of diversity in professional settings through their adherence to diversity and inclusion policies, but largely impotent at actually increasing the number of Black accountants in the field. Why is it so difficult to have honest talks about race and racism in the accounting workspace? Conceivably it is because when we do address taboo topics difficult assumptions of racial difference must be addressed. For example why are Black accountants from historical Black Colleges commonly regarded as substandard? Why does the idea exist that the best Black students go to other professions such as the law or medicine, leaving only a mediocre talent pool of Black accounting candidates? An assumption not made of white candidates. In addition, infrequently mentioned issues of ebonics and dress converge to position the Black professional as too ethnic and therefore too inauthentic to be considered a real accountant. Isolation from mentoring opportunities by Black seniors heightens seclusion, hindering the careers of Black accountants. Neither is race the sole arbiter of subjugation. While white women have shown significant progress Black women have not shared in this reward, receiving little help or proportional benefits such as career advancement gained by white peers.

The value of the CRT standpoint is its ability to directly address the uncomfortable reality of racial disparity, seeking to mainstream discourse on race rather than avoid the topic. If meaningful diversity and inclusion policy is to be attained and actual numbers of Black professionals to increase to parity with that of whites then CRT in accountancy becomes an emancipatory agenda to promote success and liberty for all, the details of which I now turn.

\section{Critical Race Theory}

CRT was originally formulated from a lack of acknowledgement of the significance of race and racism in discussions in and around Critical Legal Studies in the 1980s. In a very basic sense CRT centralizes race and racism in discourse. As Solórzano and Yosso (2009) argue in relation to the field of education:

"Critical Race Theory advances a strategy to foreground and account for the role of race and racism in education and works toward the elimination of racism as part of a larger goal of opposing or eliminating other forms of subordination based on gender, class, sexual orientation, language and national origin" (p. 132).

This article applies the same rationale to the field of accountancy utilizing a number of core canons of CRT lore as a critical lens to reveal 
processes of subordination. Firstly, race and racism are viewed as predominant organizing features of society (including the profession) that are permanent in essence. Secondly, race is considered as one inequality amongst a multitude of many; major ones being those of gender and class but to name a few. CRT recognizes that no one disadvantage is privileged greater than any other and that race is just a lens to view a nexus of other inequalities. Thirdly, CRT is oppositional to ideologies of racial objectivity and colorblindness. Ideas of the inherent pluralism of society are challenged, instead it is argued that notions of meritocracy are self- serving; advantaging only those in power. Fourthly, commitment to advancing social justice is a strategic element in the eventual removal of racism, sexism and classism. A focus is made on empowering the subordinated with numerous types of resistance. Fifthly, the ahistoricim of society toward racism is rejected. Past wrongs can and do inform present ones, if history is ignored we are doomed to repeat past mistakes. Sixthly, experiential knowledge is valued as vital to understanding oppression in its many forms. Finally, the combination of a number of theoretical frameworks (for example Feminism and Marxism) are key to examining the underlying root of inequality across race, gender and class. An adaptable critical lens must match the fluidity of oppression. CRT does not privilege one epistemological approach over another but in fact uses all available disciplines to better understand the major inequities of subordination. In the next section a number of the approaches outlined above are used to explore the daily experience of racialized processes framing accountancy.

\section{Everyday Racism}

As mentioned earlier the CAE symposium noted the importance of subtle racism as an important but forbidden subject, seldom addressed, but recognized as an underlying disadvantage for Black accountants. This indirect racism is structural in nature, representing the shared inability of an institution to give suitable professional service to those racialized as Other (Pilkington, 2004). As individual racism it hides in plain sight, where policies of an organization often work against the interests of minority groups unintentionally, promoting a shadow culture of domination that is exclusionary in nature.

This all-pervasive aspect of a racism that is institutional and understated is well documented by Philomena Assed who reveals the damage of workaday racist practice to Black workers. The daily racist joke or comment concerning inappropriate ethnic attire serves as a paper cut to the professional self-worth of the Black worker (Essed, 1991). By itself it is inconsequential but over time a thousand such cuts mark professional life as intolerable, leading to a 'death of the soul' in the workplace. Day by day, 
hour by hour one's self worth is significantly diminished, in acts of slight racism defined as Microaggressions. They are daily conversational, nonconversational insults or jibes, either deliberate or accidental, communicating aggressive, disparaging, or pejorative messages (Sue et al., 2007; Sue, 2010). Everyday snubs demean and spotlight negative difference at a personal or group level, continually reminding the stigmatized that they do not belong.

Microaggressions can be separated into three variants. Firstly, microassualts are often conscious verbal or non-verbal deliberate harmful attitudes and opinions conveyed to subordinated groups. It marks an intended hurtful attack, old-fashioned direct racism upon group identity by namecalling, evasive behavior and direct prejudiced action. For example, in a study of Black British accountancy by Lewis (2012) a Muslim accountant is jokingly offered pork sandwiches or chips that is forbidden in Islamic teaching. Secondly, unconscious microinvalidations are announcements that reject and invalidate the lived experience of the subordinated. The perpetrator suggests that the racialized Other is a foreigner, an alien in their own land. Yet simultaneously proffer that they are themselves raceless, denying their own individual racism (Lewis, 2012). Sian notes that in the white dominated Kenyan accounting profession:

"The colonial accounting firms had refused to hire non-white trainees arguing that clients would not accept them" (Sian, 2007, p. 858).

The above microinvalidation expressed by the client forms the business case for the exclusion of native Black accountants from white Kenyan accountancy, the accountancy firm is simply engaging in business. It makes natural business sense to reject Blacks (or lose the client) thus allowing the firm to rationalize its own institutionally racist exclusionary practice. Thirdly, microinsults declare offensive and thoughtless behavior with the aim of degrading a person's heritage. Negative racial tropes define the intelligence of the Black worker, along with a belief in their inherent second-class status and inherent criminality.

Often for the Black accountant racial battle fatigue is the result of a continual war of resistance against ingrained racist structures representing a draining daily fight to retain a positive sense of self. White speak engaged in the office, the forever suit wearing Black professional, all become characteristic features of the conflict against microaggressions. Only ones cultural community acts as reprieve, where use of ebonics or showing ones true ethnic face will not harm ones shot at the C-suite. It is a safe space of belonging that is needed, where the self can heal. A space not currently represented by the accountancy profession, a troubling thought indeed.

These are the 'ties that bind' many Black accountants, preventing access into the profession or successful career progression through it. The 
sheer volume of white accountants is itself an environmental microagression, a non-verbal cue that Blacks are not welcome without a single syllable being uttered. It is simply understood that accountancy is no place for Black folk. But why is this the case? Why should this be the way of things?

Next we turn to the idea of the Whiteworld of accounting, one that is seldom perceived, to examine how ingrained white cultural norms saturate the profession; perpetuate microaggressions and make discourse on race or racism all but invisible and inconsequential to the majority of whites within it.

\section{The Whiteworld of Bean Counting}

So, what exactly is Whiteworld? It seems so pejorative. It represents white normativity, that is to say the way western society defines standards of objectivity, of merit, of worth, that are saturated by white cultural mores. Universal standards of female beauty adhere to a white European template of long straight hair, small buttocks, straight nose etc. The powerful older white male is a euphemism for security, trust and success. He embodies the taken for granted invisible cultural assumption that the white way is the right way; it's the way it's always been.

Within accountancy codes of practice demand women wear appropriate suits, keep hair in an expected eurocentric manner, speak professionally at all times to be taken seriously in the work environment or pay the ultimate price, being positioned as inauthentic. Blacks must conform to white cultural practice, fit with white expectations. This is a whiteness of things, pervading all as the only authentic measure of society and the only benchmark to be met. This is the very definition of modern socially acceptable, but imperceptible white supremacy; total hegemonic domination over ones own ontology, as opposed to that of rough, uneducated, barbaric racism associated with Nazi skinheads. To be white is to be given the benefit of doubt in all things. It is the essence of privilege seldom seen by those who possess it, found in the majority of spaces of power, wealth and success, the true supremacy that exists everywhere and nowhere.

For accountancy, supremacy is the institutional whiteness of organizations. A chronicle by Barbara Flagg telling the tale of the poor progress of a Black female accountant accurately unpacks how whiteness in the workplace diminishes Black career chances. She outlines that 'racelessness' is fundamental to whiteness, referred to as the transparency phenomenon, where most whites in fact externalize race and therefore do not consider themselves as a distinct race. When race is considered it is to speak about people of color not themselves, the very essence of Othering. Therefore, whiteness is transparent in interactions with other whites, invisible, becoming opaque in the imaginary only when compared to the 
color of non-whites. The assumption of whiteness as racelessness hides decision-making, behavior and cultural norms that are specifically pro white, enabling them instead to be misrecognized as racially neutral (Flagg, 1997).

This is how whiteness becomes foundational but invisible in accountancy, able to suppress the needed conversation around race and poor Black representation. Whiteness confirms the rhetoric of meritocracy. It demands that equal racial representation must require a business case since race and racism is not a central problematic for the institution. Since it is people of color that have race then a fiduciary argument must be made for the special consideration of race in neural business matters. Does having greater racial representation favor the bottom line? If not then why bother seriously with diversity and inclusion agendas?

In a globalized world firms who do not include difference will lose market share and clients. At the very least the accountancy profession must be seen to fight the moniker of being 'Pale and male' but diversity and inclusion policy is undermined by superficial analysis of endemic racism. To increase diversity firms seek institutionally acceptable Blacks who are not culturally therefore authentically Black. This can be seen in the hiring of many African and Caribbean accountants for director and senior level positions in preference to U.S Blacks. African American Blackness is authentic Blackness and therefore particularly unpalatable to the conventions of the Whiteworld of accountancy. Whiteness devalues African American culture through specific microinvalidations found in social space, for example around the water fountain where jokes of the nappy haired accountant can be heard. Accent and cultural practice of non-African American Blacks circumvents this, the institution now has Blackness (a Black face) that is not really Black, allowing for career progression of an acceptable Blackness that becomes tangible proof of inclusion and diversity at the highest level. Further, because these good Blacks do succeed it reinforces microaggressive assertions of the inherent incompetence of African Americans, proving their unsuitability to the field. This keeps Black representation at the highest positions low but allows for some accounting institutions to prove that their policies work, they are trying hard, they will get proportional representation one day, but not yet. Implicitly it is suggested that it is the natural deficit of African American Black culture that explains low historic numbers in the industry.

Self-described attributes of the profession such as neutrality and technocracy lend themselves to being seen as characteristics of whiteness. White males embody the very image of disinterested neutrality, inherently fair and unbiased. Contrastingly, Blacks tend to bring cultural bias to the decision-making process making their decisions consistently suspect. Trust cannot easily be ascribed to the Black professional and can easily be 
revoked. The white male is the arch technocrat, while the Black male the arch suspect in the lineup. Since the Black male does not have the privilege of being assumed to be competent his work it must be checked, surveillance of his activity engaged in. He is very far removed from the image of the autonomous disinterested bureaucrat vital to bringing new clients to the business. Yet for career progression to occur (and a number of successful African American accountants do exist), the deficit of Black professional identity must be managed and reworked into valuable capital, which we will explore in detail later in the next section.

\section{Fitting in For the Black Accountant - Working Your Identity}

If success for Black accountants is so difficult then the question must be asked how do some succeed and reach the partnership level? To foster career success within the confines of an institutionally racist environment one must be chameleon like in nature, to be able to mold oneself to ever changing requirements of acceptance. This requires identity work.

As alluded to earlier the archetype of the professional accountant is the white middle class male, whiteness affords him neutrality and assumed competence making him the benchmark to be met in all matters. Identity work for the Black professional is a project to whiten, raise one's class, and if required masculinize to fit to the ascribed benchmark of the field. In a practical sense this does not necessarily mean selling out, Blackness is too hypervisible to ever be erased. Identity work is the labor of comfort management. When doubt is automatically assumed about Black identity then this suspicion must be reduced, which is a matter of deflecting racial tropes away and accentuate positive actions where possible. For example the Black female accountant at a meal celebrating a difficult audit may pay for the meal and over tip to debunk the stereotype that Black women are cheap and do not tip. The Black male professional who never displays open anger in any form in the workplace does so to debunk the myth that Black men are all emotionally volatile and physically violent. In essence special pleading is made to whiteness that these particular Blacks are not like all the rest. These Blacks are special. Of course a tight rope is walked that can revoke this temporary privilege at anytime should codes of accepted racial and gender behavior be contravened. This is very much a basic outline of identity work that must be engaged in for professional Black success. Carbado and Gulati provide further excellent in-depth exploration of the various strategies and techniques employed by the gendered and raced professional involved in working their identity (Carbado \& Gulati, 2013).

So to be a Black professional in accountancy is to be hypervisble within a white environment. It is to be mistrusted no matter how slightly most of the time. It is not to inherently possess privilege but to be required to 
earn it, time after time. Skepticism about competency and commitment is naturally ascribed to the Black male professional while trust; proficiency and success are naturally expected of his white counterpart. Professional norms, company culture and deportment are in fact codes of whiteness that the Black other physically contravenes through not being an in-group member. Microagressions are symptomatic of this reality. Microaggressive jokes are banter; ethnic dress is regarded as unprofessional attire, making successful navigation of the corporate ladder difficult and entrance into the profession harder still. The fight for workplace acceptance is a daily battle. Specific processes of how Black accounting identity is worked in the field are still very much a mystery, requiring much research not undertaken. The CRT approach begins to suggest potentially how success might be fostered, pitfalls avoided and C-suite doors opened.

\section{Conclusion}

Historically, the academy and industry have superficially chronicled Black accounting exclusion in the United States and elsewhere, leaving the core mechanics of institutional racism unproblematized. The deficit of Black accountants is unaccounted for in any great detail, as we seem happy to count the white beans, while ignoring the Black. This paper identifies the very real need for a Critical Race Theory agenda concerning the accountancy profession to address this issue, to shine light on the imperceptible regions of subordination limiting present and future Black entry into and progression through the field. I argue that whiteness is an organizing feature of the accountancy profession, providing a fertile ground for a myriad of microaggressions against Black professionals, reducing career success and self-worth in equal measure. To minimize institutional racism the Black accountant often engages in identity work to position their professional self closer to the white institutional ideal demanded by the Whiteworld of accountancy, yet at what psychological cost?

It is against this backdrop that we must chart a pragmatic framework for greater Black representation in the field, focusing on the success of Black accountants in particular. The rhetoric of meritocracy must be placed in within a critique of the whiteness of accountancy. Although this assessment may seem overly negative of the profession and be vulnerable to accusations of reverse racism (privileging Blacks over whites is just as unfair), it is instead a realistic assessment of the parlous state of Black representation in the field. Change can occur and has done so before. As others have shown, gender representation in accountancy was once dire but significant progress to increase female accountants has been made over the last one hundred years. Yet even here current institutional sexism hinders the career 
opportunities of many female accounting professionals particularly as they strive for partnership (Kirkham, 1992).

Accounting academics have a vital role to play; researchers must increase the amount of both quantitative and qualitative work in the area. Research must become the bedrock of fundamental change within the industry. The basis for this race-based focus must not be that of the business case that alludes only to the bottom line. Accountancy is more than a mere technocracy of neutral numbers and value free economic information; like other professions it is sociological in practice. The values of society both good and bad inculcate the field, defining the very nature of the profession. Therefore to focus on race and racism is to examine the very nature of accountancy, its function, its purpose, its future. It is to make sure that no black or white bean is left unaccounted for. It is to locate the profession as a positive and active agent of social justice within society rather than as a passive observer. A role accountancy must rise to meet.

\section{References:}

Annisette, M. (2000). Imperialism and the professions: The education and certification of accountants in Trinidad and Tobago. Accounting Organisations and Society, 25, 631-659.

Bakre, O.M. (2006). Second attempt at localising imperial accountancy: The case of the Institute of Chartered Accountants of Jamaica (ICAJ) (1970's1980s). Critical Perspectives on Accounting, 17, 1-28.

Bureau of Labor Statistics. (2014). Labor force characteristics by race and ethnicity, 2013, pp. 1-59. U.S. Bureau of Labor Statistics.

Carbado, D.W., \& Gulati, M. (2013). Acting white: Rethinking race in "postracial" America. New York: Oxford University Press.

Essed, P. (1991). Understanding everyday racism: An interdisciplinary theory. London: Sage Publications.

Flagg, B. J. (1997). Transparently white subjective decisionmaking: Fashioning a legal remedy. In R. Delgado and K. Stefancic (Eds.). Critical White Studies: Looking Behind the Mirror, Philadelphia: Temple University Press.

Gillborn, D. (2005). Education policy as an act of white supremacy: Whiteness, critical race theory and education reform. Journal of Educational Policy, 20, 485-505.

Hammond, T.A. (2002). A white-collar profession. University of North Carolina Press.

Hammond, T.A., Arnold, P.J., \& Clayton, B. (2007). Recounting a difficult past: A South African accounting firm's experiences in transformation. Accounting History, 12, p. 253.

Hylton, K. (2009). 'Race' and sport: Critical race theory. Oxford:Routledge. 
Kirkham, L.M. (1992). Integrating herstory and history in accountancy. Accounting Organisations and Society, 17, 287-297.

Ladson-Billings, G. (2003). Lies my teacher still tells: Developing a critical race perspective toward the social studies. In G. Ladson-Billings (Ed.), Critical race theory perspectives on social studies: The profession, policies, and curriculum. Connecticut: Information Age Publishing, Inc.

Ladson-Billings, G. J., \& Tate, W.F. (2006). Toward a critical race theory of education. In A.D. Dixon and C.K. Rousseau (Eds.), Critical race theory in education: All God's children got a song. Abingdon: Routledge.

Lewis, A.M. (2012). A critical analysis of the black accounting experience in the U.K.: Tales of success and failure in the British professional workplace. Saarbrucken: Lambert Academic Publishing.

Malone, F.L. (2001). Perception of professional acceptance and commitment of black accountants [Online]. New York: New York Society of State CPAs. (http://www.nysscpa.org/cpajournal/2001/1100/dept/d116801.htm [Accessed 11/17 2012]).

Pilkington, A. (2004). Institutional racism in the academy? Comparing the police and university in Midshire." In D.I. Law (Ed.). Institutional Racsim In Higher Education.

Phillips, D., \& Turney, L. (2004). Institutional racism in higher education. Stoke on Trent: Trentham Books.

Ross, F., \& Traub, L. (2008). Expanding the ranks of African-American CPAs: A report on the CPA examination summit. Journal of Accountancy [Online].

(http://www.journalofaccountancy.com/issues/2008/feb/expandingtheranksof africanamericancpas.htm [Accessed 10/20/2014]).

Ross, F.K., \& Traub, L. (2010). Retaining African Americans in the accounting profession: A success model. Howard University School of Business.

Sian, S. (2007). Reversing exclusion: The Africanisation of accountancy in Kenya, 1963-1970. Critical Perspectives on Accounting, 18(7), 831-872.

Solórzano, D.G., \& Yosso, T.J. (2009). Critical race methodology: Counterstorytelling as an analytical framework for educational research. In E. Taylor, D. Gillborn, and G. Ladson-Billings (Eds.), Foundations of critical race theory, pp. 131-147. London: Routledge.

Sue, D.W. (2010). Microaggressions and marginality: Manifestation, dynamics, and impact. New Jersey: John Wiley \& Sons.

Sue, D.W., Capodilupo, C.M., Torino, G.C., Bucceri, J.M., Holder, A.M.B, Nadal, K.L., \& Esquilin, M. (2007). Racial microaggressions in everyday practice. American Psychologist, 62, 271-286.

Tysiac, K. (2012). In pursuit of inclusion. Journal of Accountancy, June, 8490. 
European Journal of Contemporary Economics and Management

December 2015 Edition Vol.2 No.2

Uche, C.U. (2002). Professional accounting development in Nigeria: Threats from the inside and outside. Accounting Organisations and Society, 27, 471496. 